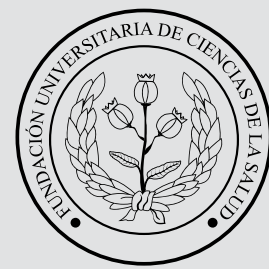

FUCS
Re

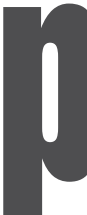
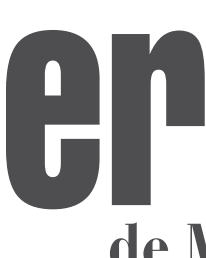

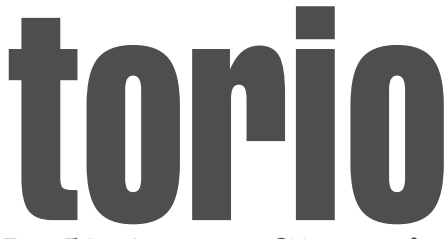

de Medicina y Cirugía
80

(Núm. Supl.1)

2021

ISSN: 0121-7372 • ISSN electrónico: 2462-991X

Artículo de revisión

\title{
Correlación entre las pruebas PCR y antígeno y el contagio por COVID-19 en Colombia
}

Jorge Enrique Díaz-Pinzón ${ }^{a}$

\section{Correlation between PCR and antigen tests and COVID-19 infection in Colombia}

${ }^{a}$ Ingeniero. Magister en Gestión de la Tecnología Educativa, Especialista en Administración de la Informática Educativa. Docente de matemáticas e Investigador, Secretaría de Educación de Soacha, Cundinamarca.

\section{R E S U M E N}

Introducción: en diciembre de 2019, en la ciudad de Wuhan, provincia de Hubei en China, se produjo un brote de casos de neumonía de origen desconocido, enfermedad denominada, al presente, COVID-19. El SARS-CoV-2 se trasfiere por contacto persona a persona y a través de secreciones de personas infectadas, principalmente gotitas respiratorias. Objetivo: mostrar si hay alguna correlación de las pruebas PCR y antígeno para COVID-19 y los contagios por COVID-19 entre el periodo comprendido entre 1 de enero a 22 de abril 2021. Metodología: esta investigación se centró en las muestras de PCR y antígeno procesadas para COVID-19 y el número de contagios con la información proveniente del Instituto Nacional de Salud. Resultados: el p-valor de las pruebas, para las variables muestras de PCR y antígeno, y contagios por COVID-19 que es de 0,000, es menor a $\alpha=0.01$, de esta manera se acepta Ha, es decir la prueba de correlación de Pearson nos indica que existe relación entre las pruebas PCR y antígeno para COVID-19 y el número de contagios por COVID-19. Conclusión: el uso de pruebas PCR y antígeno se relacionan con el número de contagios por COVID-19, es decir, que en la medida que aumentan los valores de pruebas PCR y antígeno también aumentan los casos de contagio por COVID-19 y viceversa.

Palabras clave: correlación, Pearson, COVID-19, SARS-CoV-2, pandemia, pruebas diagnósticas, PCR, antígeno.

(C) 2021 Fundación Universitaria de Ciencias de la Salud - FUCS. Este es un artículo Open Access bajo la licencia CC BY-NC-ND (http://creativecommons.org/licenses/by-nc-nd/4.0/).

INFORMACIÓN DEL ARTÍCULO

Historia del artículo:

Fecha recibido: abril 26 de 2021 Fecha aceptado: junio 8 de 2021
Autor para correspondencia: Ing. Jorge Enrique Díaz Pinzón jediazp@unal.edu.co
DOI

10.31260/RepertMedCir.01217372.1207 
Introduction: On December 2019, there was an outbreak of cases of unknown origin pneumonia, detected in Wuhan city, Hubei Province, China, currently known as COVID-19 disease. SARS-CoV-2 is transmitted from person to person contact and through secretions of infected persons, mainly respiratory droplets. Objective: to show if there is any correlation of PCR and antigen testing for COVID-19 and COVID-19 infections between January 1 and April 22 2021. Methodology: this research focused on the PCR and antigen samples processed for COVID-19 and the number of infections, using the data released by the National Institute of Health. Results: the p-value of the tests for variables PCR and antigen samples, and COVID-19 infections, which is 0.000 , is less than $\mathrm{a}=0.01$, thus the hypothesis ( $\mathrm{Ha}$ ) is accepted, that is Pearson's correlation indicates there is a relationship between PCR and antigen tests for COVID-19 and the number of COVID-19 infections. Conclusion: the use of PCR and antigen tests is related with the number of COVID-19 infections, that is, as the values of PCR and antigen tests increase, the number of COVID-19 infections also increase and vice versa.

Key words: correlation, pearson, COVID-19, SARS-CoV-2, pandemic, diagnostic tests, PCR, antigen.

(C) 2021 Fundación Universitaria de Ciencias de la Salud - FUCS. This is an open access article under the CC BY-NC-ND license (http://creativecommons.org/licenses/by-nc-nd/4.0/).

\section{INTRODUCCIÓN}

En diciembre de 2019, en la ciudad de Wuhan, provincia de Hubei en China, se produjo un brote de casos de neumonía de origen desconocido, enfermedad denominada, al presente, COVID-19. ${ }^{1}$ El SARS-CoV-2 se trasfiere por contacto persona a persona y a través de secreciones de personas infectadas, en especial gotitas respiratorias. ${ }^{2}$ Cuando la infección se amplía a los pulmones, la neumonía (evidenciada por las imágenes radiográficas) puede ser moderada o grave y en los casos con mala evolución clínica se exhibe insuficiencia respiratoria que requiere ventilación mecánica, shock séptico, coagulación intravascular y fallo multiorgánico (incluyendo fallo renal). Por ende, el contagio puede ocurrir por aspiración de las gotitas o por contacto con superficies contaminadas por ellas, que consienta al virus y accede a las mucosas de boca, nariz y ojos. ${ }^{3}$

Debido a su condición de pandemia, es indispensable contar con métodos de diagnóstico confiables para la delimitación de esta infección viral, lo que favorece a su diagnóstico oportuno, y además sujeta la posibilidad de clasificar a individuos como falsos negativos, los que podrían propagar la enfermedad. ${ }^{4}$ La masificación de las pruebas es una de las estrategias más favorecidas para contener y eventualmente mitigar la difusión de la pandemia. ${ }^{5}$ Pese al corto tiempo transcurrido desde el inicio de la pandemia, un gran número de trabajos académicos instan en la importancia de las pruebas, en particular PCR, para apartar a las personas infectadas -tengan o no síntomas- y rastrear sus cadenas de contagio. ${ }^{6-8}$

En la realidad existe un sinnúmero de métodos diagnósticos para COVID-19, desde pruebas para la localización del virus, algunos con ventajas sobre la sensibilidad y especificidad, mientras otros con desventajas por costos, infraestructura y personal sanitario competente para aplicarlos; si bien el modo de elección es una técnica molecular de detección y amplificación de ácidos nucleicos o material genético como el RT-PCR, también es necesario acomodar pruebas rápidas, simples e imaginativamente con alta sensibilidad y precisión que se puedan practicar a gran escala para brindar un diagnóstico precoz y realizar un mejor manejo clínico y epidemiológico de los pacientes. ${ }^{9}$

\section{Pruebas de detección de ácidos nucleicos: PCR}

"La PCR con transcriptasa inversa (RT-PCR o qRT-PCR si se cuantifica en tiempo real) es una técnica molecular de detección directa de material genómico por amplificación de ácidos nucleicos" ${ }^{10}$

\section{Pruebas de detección de antígenos (Ag)}

"Se basan en la detección de proteínas virales específicas del SARS-CoV-2 como la proteína $\mathrm{N}$ y las subunidades $\mathrm{S} 1$ o S2 de la proteína espícula (S). Las muestras biológicas usadas proceden de exudado nasofaríngeo, orofaríngeo o de esputo. Según estudios publicados, la carga viral es mayor en esputo y nasofaringe, siendo más elevada en estadios iniciales de la infección" ${ }^{10}$ En la figura 1 se aprecia como se realiza la prueba COVID-19, su evolución, fiabilidad, utilidad y sus limitaciones. ${ }^{11}$

En el análisis de los estudios clínico-epidemiológicos brota con frecuencia la obligación de establecer la relación entre dos variables cuantitativas en un grupo de sujetos. Los objetivos de dicho análisis suelen $\operatorname{ser}^{12}$ : a) establecer si las dos variables están correlacionadas, es decir si los valores de una tienden a ser más altos o bajos, para más altos o bajos de la otra variable; b) poder pronosticar el valor de una variable dado un valor determinado de la otra variable y c) estimar el nivel de correspondencia entre los valores de las dos variables. 


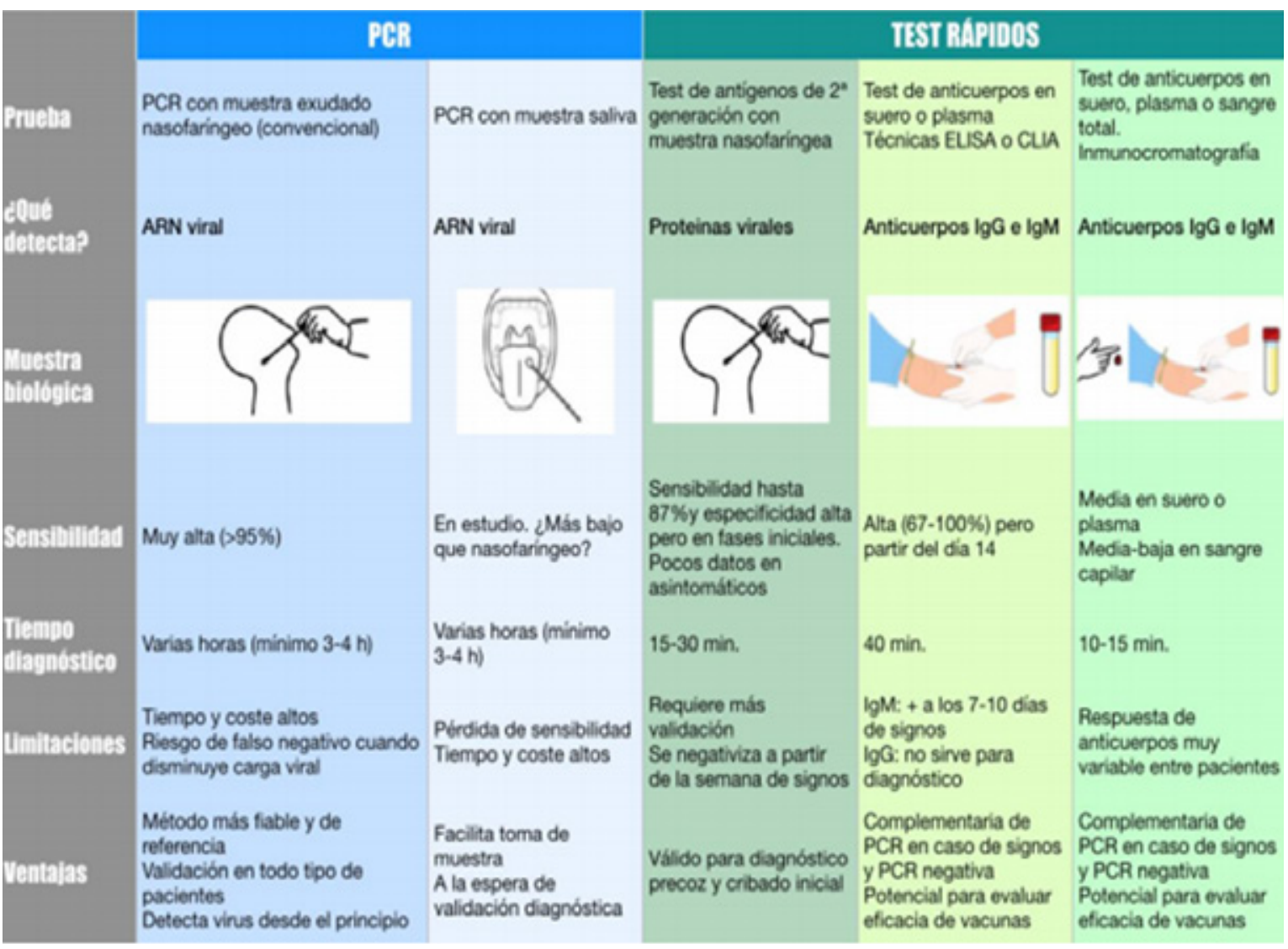

Figura 1. Test COVID-19. Evolución, fiabilidad, utilidad y limitaciones. Fuente: Organización Colegial de Dentistas de España. ${ }^{11}$

\section{Pruebas de detección de ácidos nucleicos: PCR}

La cuantificación de la fuerza de la relación lineal entre dos variables cuantitativas se estudia por medio del cálculo del coeficiente de correlación de Pearson. Este coeficiente oscila entre $-1 \mathrm{y}+1$. El valor -1 indica una relación lineal o línea recta positiva perfecta. Una correlación próxima a cero indica que no hay relación lineal entre las dos variables. ${ }^{12}$ En la tabla 1 se aprecia la escala de coeficiente de correlación de Pearson. ${ }^{13}$

Tabla 1. Escala de coeficiente de correlación de Pearson

\begin{tabular}{|c|l|}
\hline Valor & \multicolumn{1}{|c|}{ Significado } \\
\hline-1 & Correlación negativa grande y perfecta \\
$-0,9$ a $-0,99$ & Correlación negativa muy alta \\
$-0,7$ a $-0,89$ & Correlación negativa alta \\
$-0,4$ a $-0,69$ & Correlación negativa moderada \\
$-0,2$ a $-0,39$ & Correlación negativa baja \\
$-0,01$ a $-0,19$ & Correlación negativa muy baja \\
0 & Correlación nula \\
0,01 a 0,19 & Correlación positiva muy baja \\
0,2 a 0,39 & Correlación positiva baja \\
0,4 a 0,69 & Correlación positiva moderada \\
0,7 a 0,89 & Correlación positiva alta \\
0,9 a 0,99 & Correlación positiva muy alta \\
1 & Correlación positiva grande y perfecta \\
\hline
\end{tabular}

El objetivo de esta investigación es mostrar si hay alguna correlación de las pruebas PCR y antígeno para COVID-19, con los contagios por COVID-19, en el periodo 1 de enero a 22 de abril 2021.

\section{METODOLOGÍA}

El trabajo de investigación se efectuó mediante un tipo experimental que es el siguiente: “aquella que permite mayor seguridad al establecer relaciones de causa a efecto pues presenta una visión general y aproximada del objeto de estudio, además de contar con una investigación cuyo diseño establece un método experimental habitual del conjunto de las normas científicas", Monje (2011) citado por Díaz. ${ }^{14}$ Según Shuttleworth citado por Díaz ${ }^{15,16}$, menciona que "regularmente a estos experimentos se los nombra ciencia verdadera y manejan medios matemáticos y estadísticos cotidianos para evaluar los resultados de modo concluyente. Todos los experimentos cuantitativos utilizan un formato estándar con algunas pequeñas diferencias interdisciplinarias para generar una hipótesis que será probada o desmentida. Esta hipótesis debe ser demostrable por medios matemáticos y estadísticos y constituye la base alrededor de la cual se diseña todo el experimento". 


\section{POBLACIÓN}

La información se obtuvo de la página web del Instituto Nacional de Salud ${ }^{17}$ de los informes diarios de las pruebas para PCR y antígeno, y los casos de contagio por COVID-19 entre el periodo comprendido entre 1 de enero a 22 de abril 2021.

\section{FORMULACIÓN DE HIPÓTESIS}

La hipótesis del presente trabajo de investigación se diseña como una relación causal y se enuncia de la siguiente forma: a) hipótesis alterna (Ha), existe relación entre las pruebas PCR y antígeno para COVID-19 y el número de contagios por COVID-19 en Colombia; b) hipótesis nula (Ho), no existe relación de las pruebas PCR y antígeno para COVID-19 y el número de contagios por COVID-19 en Colombia. Nivel de significancia: $=1 \%=0,1$.

Toma de decisión: sí el p-valor < a es aceptar Ha, entonces rechazamos la hipótesis nula y nos quedamos con la hipótesis del investigador (Ha).

\section{RESULTADOS}

En la figura 2 se aprecian los casos diarios de pruebas PCR y antígeno y el número de contagios por COVID-19, durante el período 1 de enero hasta 22 de abril 2021.

En la tabla 2 se aprecia el p-valor de las pruebas, para las variables muestras de PCR y antígeno, y contagios por COVID-19 que es de 0,000, es menor a $a=0.01$, de esta manera se acepta Ha, es decir la prueba de correlación de Pearson nos indica que existe relación entre las pruebas PCR y antígeno para COVID-19, y el número de contagios por COVID-19 en Colombia, durante el período comprendido entre el 1 de enero a 22 de abril 2021.

En la figura 3 se aprecia el diagrama de correlación entre contagio por COVID-19 y las pruebas PCR, y antígeno que es positiva. El número de datos es igual a 112; $\mathrm{r}=0,776$; $\mathrm{p}<$ 0,001 . De esta manera según el valor $r=0,776$, se evidencia una correlación positiva alta entre las variables. La ecuación lineal está dada por: $Y=0,3125 X-6250$. Lo que se traduce que en la medida que aumentan los valores de pruebas PCR y antígeno también aumentan los casos de contagio por COVID-19 y viceversa.

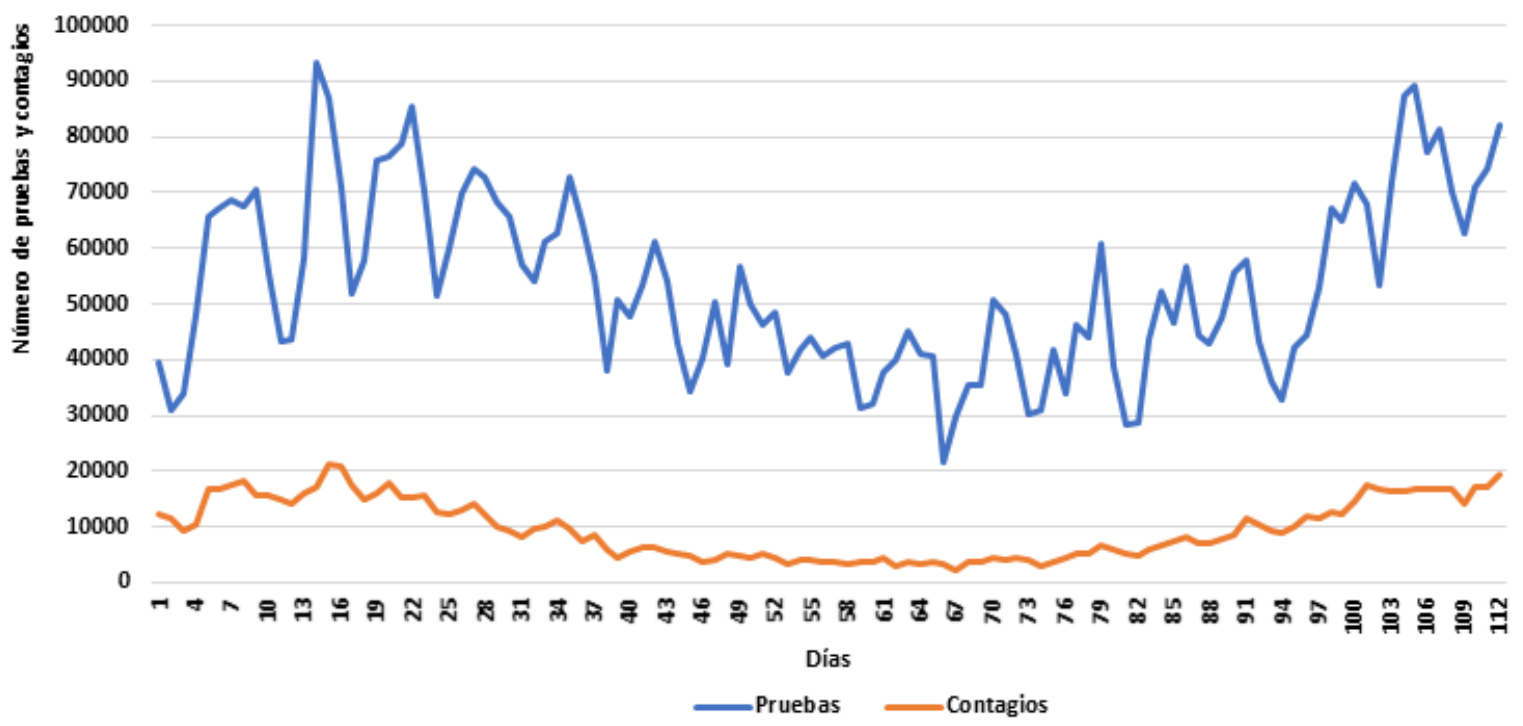

Figura 2. Pruebas de COVID-19 y contagio. Fuente: el autor.

Tabla 2. Correlación de Pearson

\begin{tabular}{|l|l|c|c|}
\hline \multicolumn{2}{|c|}{} & $\begin{array}{c}\text { Pruebas PCR } \\
\text { y Antigeno }\end{array}$ & Contagio \\
\hline Pruebas PCR & Correlación de Pearson & 1 &, $776^{\star \star}$ \\
y Antígeno & Sig. (bilateral) & 112 &, 000 \\
& $\mathrm{~N}$ & 112 \\
\cline { 1 - 1 } Contagio & Correlación de Pearson &, $776^{* \star}$ & 1 \\
& Sig. (bilateral) &, 000 & \\
& $\mathrm{~N}$ & 112 & 112 \\
\hline
\end{tabular}

**a correlación es significativa en el nivel 0,01 (bilateral). Fuente. el autor.

\section{CONCLUSIONES}

A partir de los datos analizados, se concluye que el uso de pruebas PCR y antígeno se relaciona con el número de contagios por COVID-19, es decir, que en la medida que aumentan los valores de pruebas PCR y antígeno, también aumentan los casos de contagio por COVID-19 y viceversa.

Los datos procedentes del estudio correlacional entre las variables pueden ser utilizados para predecir el número de pruebas PCR y antígeno y el número de contagios por COVID-19. Esto complementado con las fortalezas de pruebas moleculares que permiten la detección específica del SARS- 


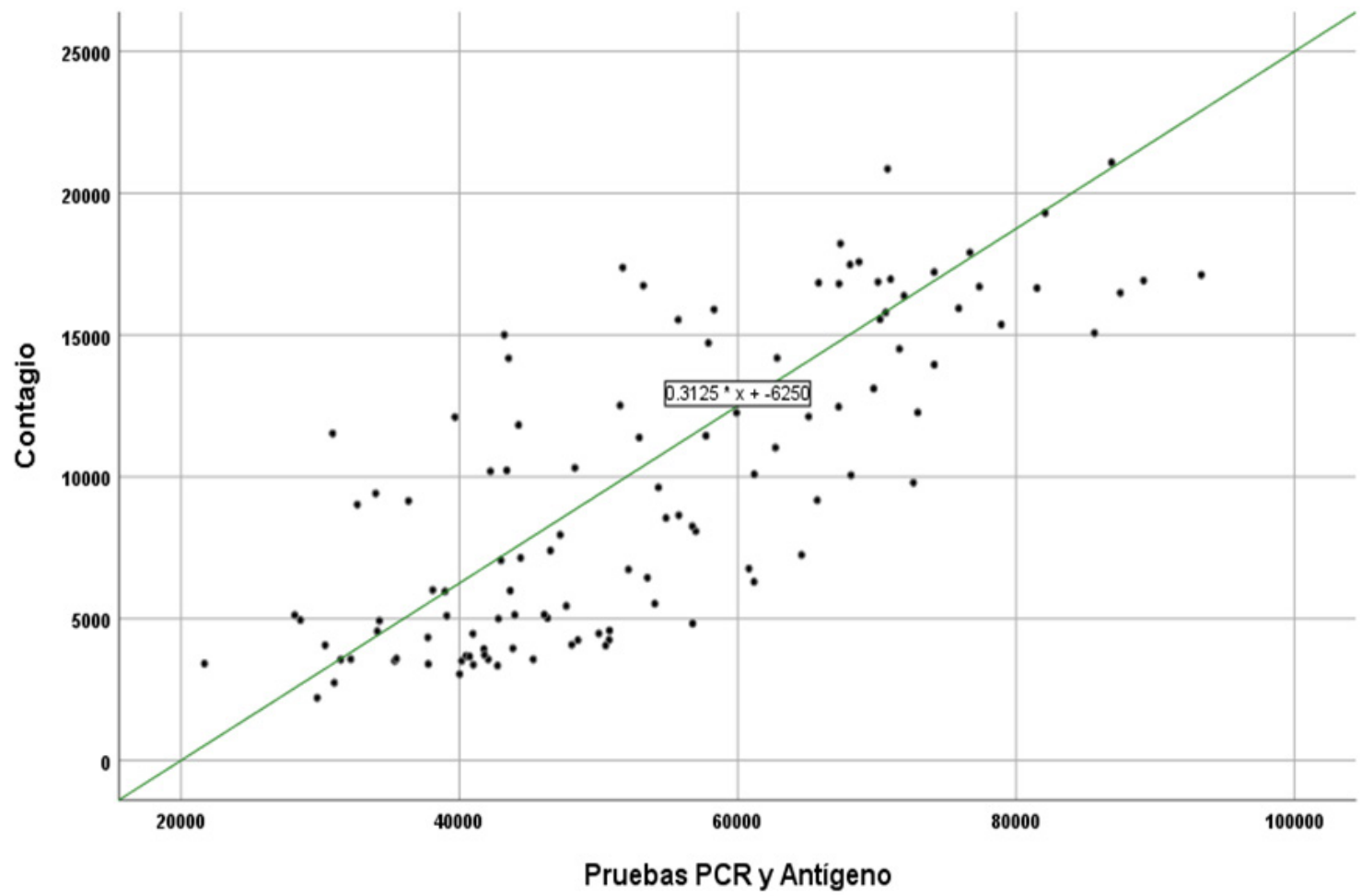

Figura 3. Diagrama de correlación por COVID-19 y las pruebas PCR, y Antígeno. Fuente: el autor.

CoV-2 con ensayos inmunológicos que estiman la respuesta inmune del hospedero, será decisivo para el diagnóstico certero y a tiempo para beneficio de los pacientes. ${ }^{18}$

\section{REFERENCIAS}

1. World Health Organization. Novel Coronavirus (2019-nCoV): situation report. World Health Organization; 2020. p. 7.

2. Prompetchara E, Ketloy C, Palaga T. Immune responses in COVID-19 and potential vaccines: Lessons learned from SARS and MERS epidemic. Asian Pac J Allergy Immunol. 2020;38(1):1-9. doi: 10.12932/AP-200220-0772.

3. Ministerio de Sanidad, Centro de Coordinación de Alertas y Emergencias Sanitarias. Información científica técnica. Enfermedad por coronavirus, COVID-19. Actualización 4 abril 2020. 2020. p. 111.

4. Aguilar- Ramírez, P. Enríquez -Valencia, Y. Quiroz-Carrillo, Valencia- Ayala, C. De León-Delgado, J. Pareja-Cruz, A. Pruebas diagnósticas para la COVID-19: la importancia del antes y el después. Horiz. Med. 2020;20(2): e1231. doi: http://dx.doi. org/10.24265/horizmed.2020.v20n2.14

5. Adhanom, T. WHO Director-General's opening remarks at the media briefing on COVID-19 [Internet]. World Health Organization; 2020 [citado 23 abril 2021]; Disponible en: https://www.who.int/ director-general/speeches/detail/who-director-general-s-openingremarks-at-the-media-briefing-on-covid-19---11-march-2020
6. Arons MM, Hatfield KM, Reddy SC, Kimball A, James A, Jacobs JR, et al. Presymptomatic SARS-CoV-2 infections and transmission in a skilled nursing facility. N Engl J Med. 2020;382(22):20812090. doi: 10.1056/NEJMoa2008457

7. Gandhi M, Yokoe DS, Havlir, DV. Asymptomatic Transmission, the Achilles's Heel of Current Strategies to Control Covid-19. N Engl J Med. 2020;382(22):2158-2160. doi: 10.1056/NEJMe2009758

8. Hellewell J, Abbott S, Gimma A, Bosse NI, et al. Feasibility of controlling COVID-19 outbreaks by isolation of cases and contacts. Lancet Global Health. 20208(4):E488-E496. doi: 10.1016/S2214109X(20)30074-7

9. Meza Calvache J, Estrada Rodríguez A, Chabusa Martínez C, Velasco Paucar V. Utilidad de Pruebas de cadena de polimerasa, pruebas rápidas y Tomografías en pacientes con Covid-19. Journal of American Health. 2020;3(2):32-39. doi: https://doi. org/10.37958/jah.v3i2.28.

10. Soldevila-Langa, L. Valerio-Sallent, L. Roure-Díez, S. Interpretación de las pruebas diagnósticas de la COVID-19. FMC - Formación Médica Continuada en Atención Primaria. 2021;28(3):167-173. doi: 10.1016/j.fmc.2021.01.005

11. Organización Colegial de Dentistas de España. Test COVID-19 su evolución fiabilidad, utilidad y limitaciones. 2020. p. 18.

12. Pita-Fernández, S. Pértega-Díaz, S. Relación entre variables cuantitativas [Internet]. Fisterra; 2021 [citado 23 abr 2021]; Disponible en: https://www.fisterra.com/formacion/metodologiainvestigacion/relacion-entre-variables-cuantitativas/ 
13. Suárez-Ibujes, M. Coeficiente de correlación de Karl Pearson [Internet]. 2021 [citado 23 abr 2021]; Disponible en: https://www. monografias.com/trabajos85/coeficiente-correlacion-karl-pearson/ coeficiente-correlacion-karl-pearson.shtml

14. Díaz-Pinzón JE. Estudio de los resultados del contagio por COVID-19 a nivel mundial. Repert Med Cir. 2020;29 (Núm. Supl.1):65-71. doi: 10.31260/RepertMedCir.01217372.1089

15. Díaz-Pinzón, J.E. Proyección del COVID-19 en Colombia. Rev. Med [Internet]. 11 de septiembre de 2020 [citado 19 de abril de 2021]; 28(1). DOI: https://doi.org/10.18359/rmed.4702
16. Díaz-Pinzón, J.E. Soporte técnico de simulación Phet en la enseñanza y aprendizaje de fracciones equivalentes. Revista de investigaciones Universidad del Quindío. 2016;28(2):31-41. doi: https://doi.org/10.33975/riuq.vol28n2.6

17. Instituto Nacional de Salud. Coronavirus (COVID-19) en Colombia [Internet]. 2021 [citado 23 abr 2021]; Disponible en: https://www. ins.gov.co/Paginas/Inicio.aspx

18. Pérez- Abreu M, Gómez-Tejeda J, Dieguez-Guach R. Características clínico-epidemiológicas de la COVID-19. Rev Haban Cienc Méd. 2020;19(2): e_3254. 